\title{
STUDI IDENTIFIKASI PENGELOLAAN LAHAN BERDASAR TINGKAT BAHAYA EROSI (TBE) (Studi Kasus Di Sub Das Sani, Das Juwana, Jawa Tengah)
}

\author{
Rathna Wijayanti* \\ Program Studi Ilmu Ilmu Lingkungan, Program Pascasarjana Universitas Diponegoro Semarang \\ * Subdit Evaluasi Pengelolaan DAS, Direktorat Pengelolaan DAS, Dirjen RLPS, Dephut
}

\begin{abstract}
ABSTRAK
Kondisi Sub DAS Sani DAS Juwana, Jawa Tengah, saat ini sedang dalam kondisi kritis yang ditunjukkan dengan adanya banjir, sedimen, dan tingkat erosi tinggi. Untuk pengelolaan Sub DAS Sani, diperlukan studi untuk mengidentifikasikan dan mengkaji laju dan sebaran erosi, serta merumuskan urutan prioritas pengelolaan lahan berdasarkan TBE dan rekomendasi pengelolaan lahan guna kepentingan penanganan lahan.

Hasil penelitian menunjukkan besarnya laju erosi dengan tingkat erosi normal ( $<15$ ton/ha/thn) sebesar 64,64\% dari luas wilayah, dan laju erosi berat sampai dengan sangat berat sebesar 9,498\%. Berdasarkan Tingkat Bahaya Erosi (TBE), TBE dengan kategori sedang sampai dengan sangat berat seluas 4.425,92 Ha (17,42\%) sehingga membutuhkan tindakan konservasi. Sebaran laju erosi maupun TBE sedang sampai sangat berat berada di lereng atas Gunung Muria dan sebagian di Perbukitan Patiayam. Semakin berat TBE maka semakin tinggi prioritas penanganannya. Hasil sebelum dan sesudah rekomendasi menunjukkan bahwa terjadi penurunan erosi yang signifikan pada laju erosi sedang sampai sangat berat yaitu dari 258.493,20 ton/ha/tahun menjadi 10.486,58 ton/ha/tahun, atau berkurang sebesar 248.006,62 ton/ha/tahun.

Dari penelitian ini dapat disimpulkan: (1) TBE di Sub DAS Sani DAS Juwana yang memerlukan tindakan konservasi sebesar 4.425.92 Ha (17,42\%), yang terdiri dari TBE sangat berat, berat, dan sedang, tersebar di daerah yang seharusnya menjadi lahan konservasi. Erosi ini terutama disebabkan oleh konversi lahan hutan ke bukan hutan, pengelolalaan lahan pertanian kurang atau tidak memperhatikan kaidah konservasi tanah dan air, dan belum adanya kesadaran partisipasi masyarakat dalam mengelola lahannya; (2) Berdasarkan hasil rekomendasi pada unit lahan-unit lahan dengan TBE sangat berat, berat, dan sedang, laju erosi dapat dikurangi sebesar 248.006 ton/ha/tahun. Upaya pengelolaan lahan dengan teknik konservasi yang sesuai dan memadai dapat mengurangi laju erosi. Berdasarkan urutan prioritas pengelolaan lahan dan arahan fungsi pemanfaatan lahan, rekomendasi pengelolaan lahan secara mekanik untuk lereng klas I - IV menggunakan teras gulud sedangkan lereng klas $V$ menggunakan teras gunung. Untuk rekomendasi secara vegetatif, pengelolaan lahan disesuaikan dengan arahan pemanfaatan lahannya.
\end{abstract}

Kata Kunci: Daerah Aliran Sungai (DAS), Pengelolaan Lahan, Tingkat Bahaya Erosi.

\section{PENDAHULUAN}

Daerah Aliran Sungai (DAS) yang merupakan suatu ekosistem, terdiri dari berbagai komponen biogeofisik yang saling berinteraksi. Dalam DAS sebagai sistem tersebut terjadi masukan (input) yang berupa hujan dan campur tangan manusia, proses yang terjadi di dalam DAS dan keluaran (output) yang berupa produksi, limpasan, dan sedimen. Keluaran tersebut apabila berdampak positif tentunya tidak menjadi masalah, namun untuk keluaran yang berdampak negatif tentu menjadi masalah baik bagi lingkungan maupun manusia seperti erosi, pencemaran lingkungan, banjir dan lainnya..

Penggunaan lahan yang melebihi daya dukung lahan serta penggunaan lahan yang tidak sesuai dengan kesesuaian lahan tentunya akan menimbulkan degradasi lingkungan. Hal ini terjadi diberbagai tempat tidak terkecuali di DAS Juwana. Hulu DAS Juwana yang terletak di lereng Gunung Muria telah terjadi konversi lahan dari hutan menjadi bukan hutan. Konversi lahan ini 
mengakibatkan lahan kritis di bagian hulu DAS terutama yang disebabkan oleh erosi.

Berdasarkan hasil evaluasi tingkat kekritisan DAS tahun 2007, dari 6 (enam) sub DAS yang ada di DAS Juwana, Sub DAS Sani merupakan sub DAS prioritas urutan pertama (BPDAS Pemalijratun, 2007). Dengan demikian maka sub DAS ini memerlukan penanganan yang lebih serius dan lebih cepat dibandingkan dengan sub DAS lain yang ada di DAS Juwana.

Sub DAS Sani merupakan kawasan hulu DAS Juwana yang secara administratif terletak di Kabupaten Pati dan Kudus, merupakan kawasan konservasi dan lindung Gunung Muria. Luas wilayah Sub DAS Sani seluas 25.414.37 ha atau sebesar 17,33 \% dari luas DAS Juwana. Letak geografis Sub DAS Sani berada pada posisi koordinat antara $110^{\circ} 53^{\prime} 29^{\prime \prime}$ - $111^{\circ} 04^{\prime} 35^{\prime \prime}$ BT dan antara 6 $6^{\circ} 37^{\prime} 48^{\prime \prime}$ - 6 $6^{\circ} 52^{\prime} 03^{\prime \prime}$ LS.

Penelitian ini mengkaji TBE dan sebarannya di Sub DAS Sani DAS Juwana, serta merumuskan urutan prioritas pengelolaan lahan berdasarkan TBE dan menyusun rekomendasi pengelolaan lahan guna kepentingan penanganan lahan di Sub DAS Sani DAS Juwana.

\section{METODE PENELITIAN}

Data yang diperlukan berupa data sekunder didukung dengan pengamatan lapangan. Data kemudian dianalisis secara deskriptif kuantitatif dan overlay peta.

\section{Penghitungan Besarnya Laju Erosi}

Pengukuran laju erosi menggunakan pendekatan Universal Soil Loss Equation (USLE). (Wischmeier dan Smith, 1978:4)

$$
\mathrm{A}=\mathrm{RxKxLSxCxP}
$$

A adalah banyaknya tanah tererosi (ton/ha/tahun), R (faktor erosivitas hujan), K (faktor erodibilitas tanah), LS (faktor panjang dan kemiringan lereng), C (faktor pengelolaan tanaman/vegetasi), $\mathrm{P}$ (faktor pengelolaan lahan atau konservasi tanah).

Nilai laju erosi diperoleh dari hasil overlay peta-peta tematik, yaitu: Peta Kemiringan Lereng, Peta Jenis Tanah, Peta Intensitas Curah Hujan, dan Peta Penggunaan Lahan.

\section{Penentuan Urutan Prioritas Penanganan}

Urutan pengelolaan lahan ditentukan berdasarkan besarnya TBE dimana semakin berat
TBE maka semakin tinggi prioritasnya. TBE adalah perbandingan besar erosi yang terjadi dengan toleransi erosi (erosi yang masih diperbolehkan). Untuk memperoleh besarnya TBE, digunakan Tabel 1 berikut:

Tabel 1. Klas Tingkat Bahaya Erosi (TBE)

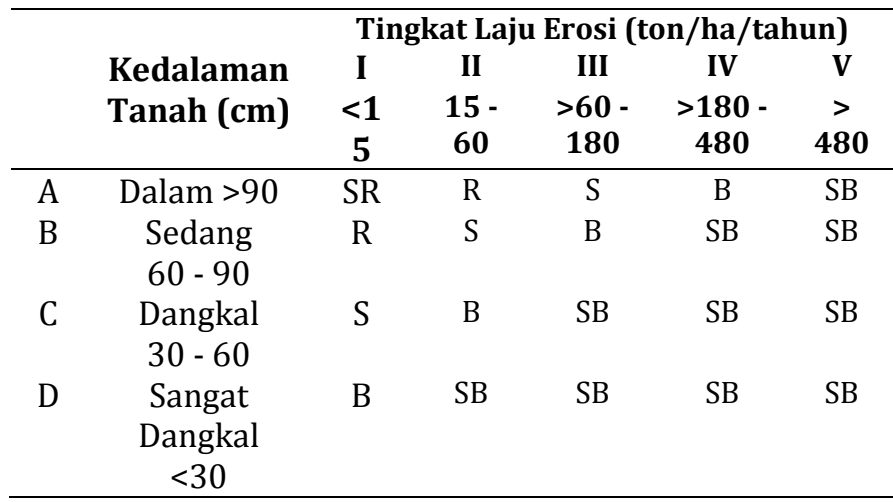

Keterangan :

$\mathrm{SR}=$ Sangat Ringan $; \mathrm{R}=$ Ringan $\mathrm{S}=$ Sedang

$\mathrm{B}=$ Berat; $\mathrm{SB}=$ Sangat Berat

Urutan prioritas pengelolaan lahan berdasar TBE disusun berdasarkan besarnya TBE disusun Tabel 2 berikut:

Tabel 2.Penentuan Urutan Prioritas Pengelolaan Lahan

\begin{tabular}{|l|c|}
\hline \multicolumn{1}{|c|}{ Klas TBE } & Prioritas \\
\hline SB (sangat berat) & I \\
\hline B (berat) & II \\
\hline S (sedang) & III \\
\hline R (ringan) & IV \\
\hline SR (sangat ringan) & V \\
\hline
\end{tabular}

\section{Rekomendasi Pengelolaan Lahan}

Rekomendasi pengelolaan lahan bertujuan agar laju erosi sama atau lebih kecil dari laju erosi yang diperbolehkan. Pertimbangan yang digunakan adalah kondisi fisik daerah, TBE, dan arahan fungsi pemanfaatan lahan.

\section{HASIL DAN PEMBAHASAN}

\section{Laju Erosi}

Besarnya erosi yang terjadi pada Sub DAS Sani adalah besarnya erosi total $\mathrm{x}$ Luas, yaitu 144,212 ton/ha/thn $\mathrm{x} 25.414,93$ ha = $3.665 .137,89$ ton/tahun, dengan laju erosi ratarata 144,212 ton/ha/thn atau $12,03 \mathrm{~mm} /$ tahun. 
Tabel 3. Laju Erosi di Sub DAS Sani

\begin{tabular}{ccccc}
\hline Klas & $\begin{array}{c}\text { Laju Erosi } \\
\text { (Ton/Ha/T } \\
\text { hn) }\end{array}$ & $\begin{array}{c}\text { Kategor } \\
\text { i Erosi }\end{array}$ & Luas (Ha) & $\mathbf{\%}$ \\
\hline I & $<15$ & Normal & $16.428,58$ & 64,641 \\
II & $15-60$ & Ringan & $4.560,44$ & 17,944 \\
III & $60-180$ & Moderat & $2.011,95$ & 7,916 \\
IV & $180-480$ & Berat & 750,495 & 2,953 \\
V & $>480$ & Sangat & $1.663,47$ & 6,545 \\
& & Berat & $\mathbf{2 5 . 4 1 4 , 9}$ & $\mathbf{1 0 0 , 0}$ \\
& Jumlah : & & $\mathbf{3}$ & $\mathbf{0}$ \\
\hline
\end{tabular}

Sumber : Analisis Data

Desa-desa dengan sebaran erosi sangat berat justru terdapat pada daerah hulu Sub DAS Sani, harusnya daerah ini berperan sebagai resapan air. Desa-desa tersebut meliputi Desa Sitiluhur, Klakah Kasian, Bageng, Plukaran, Rahtawu, Japan, Colo, Kuwukan, Cranggang, Tergo.

\section{Prioritas Pengelolaan Lahan}

Berdasar hasil analisis, luas dan sebaran TBE yang terdapat di Sub DAS Sani serta tingkat prioritas pengelolaan lahan dapat dilihat pada Tabel 4. di bawah ini :

Tabel 4. Tingkat Bahaya Erosi dan Prioritas Pengelolaan Lahan di Sub DAS Sani

\begin{tabular}{|c|c|c|c|c|}
\hline No & TBE & Luas (Ha) & $\begin{array}{c}\text { Luas } \\
(\%)\end{array}$ & Prioritas \\
\hline 1 & $\begin{array}{l}\text { Sangat } \\
\text { Ringan }\end{array}$ & $16.101,80$ & 63,36 & V \\
\hline 2 & Ringan & $4.886,60$ & 19,23 & IV \\
\hline 3 & Sedang & $2.011,95$ & 7,92 & III \\
\hline 4 & Berat & 750,50 & 2,95 & II \\
\hline \multirow[t]{2}{*}{5} & Sangat Berat & $1.663,47$ & 6,55 & I \\
\hline & & $25.414,93$ & 100,00 & \\
\hline
\end{tabular}

Sumber : Analisis Data

Tujuan pembuatan prioritas pengelolaan lahan adalah untuk efektivitas pengelolaan lahan dalam mengurangi laju erosi yang terjadi. Rekomendasi pengelolaan lahan hanya dilakukan pada unit lahan dengan TBE sangat berat (SB), berat (B), dan sedang (S), sedangkan unit lahan dengan TBE ringan (R) dan sangat ringan (SR) tidak dibuat rekomendasi pengelolaan lahan. Dari tabel 4 terlihat bahwa prioritas penanganan untuk TBE sangat berat, berat, dan sedang, maka terdapat seluas $4.425,92$ Ha $(17,42 \%$ dari total luas Sub DAS Sani).

Berdasarkan peta TBE, terlihat bahwa sebaran TBE Sangat Berat, Berat, dan Sedang sebagaian besar berada di lereng atas Muria dengan penggunan lahan didominasi oleh tegalan. Dari pengamatan di lapangan, unit lahan pada daerah ini hampir tidak memiliki sistem pengelolaan lahan yang memperhatikan kaidah konservasi, seperti pembuatan teras dan sebagainya. Apabila dilihat dari arahan fungsi pemanfaatan lahan, seharusnya sebagian besar di daerah ini merupakan kawasan lindung, kawasan penyangga, maupun kawasan budidaya tanaman tahunan, namun pada kenyataannya digunakan untuk tegalan atau tanaman semusim lainnya.

\section{Persepsi Masyarakat Terhadap Konservasi Lahan}

Hasil pengamatan dan wawancara mengenai persepsi masyarakat terhadap konservasi lahan di Sub DAS Sani diketahui sebagian besar masyarakat sadar bahwa mereka membutuhkan teknik konservasi, namun pada umumnya masyarakat belum menerapkan teknik konservasi yang diperkenalkan. Hal ini disebabkan oleh kendala biaya dan tenaga kerja, seperti pembuatan teras dan penanaman rumput.

Alasan lain adalah kurangnya pengetahuan masyarakat tentang teknik konservasi. Sebagai contoh pembuatan teras belum diterapkan karena ketakutan akan berkurangnya bidang olah. Penanaman rumput untuk tampingan teras juga ditakutkan akan mengganggu pertumbuhan tanaman ketela pohon dan kacang tanah yang merupakan tanaman utama.

Meski demikian, teknik konservasi menggunakan tanaman keras sudah mulai menerapkan seperti tanaman kopi, jati, dan sengon. Kendala utama adalah kurangnya inisiatif masyarakat untuk menyediakan bibit dan masih tingginya keinginan masyarakat untuk mengusahakan lahannya dengan tanaman semusim seperti ketela pohon dan kacang tanah, dimana tanaman ini secara sosial dan turun temurun sudah membudaya dalam masyarakat. Masyarakat tidak mau beresiko tinggi jika harus mengganti dengan komoditi lain yang belum tentu hasilnya. 
Disamping itu terdapat faktor lain yang mempengaruhi tingkat adopsi masyarakat, yaitu :

- Kurangnya pengetahuan masyarakat tentang teknik konservasi.

- Rendahnya kemampuan ekonomi masyarakat

- Sosial dan budaya mesyarakat seperti budaya menanam ketela pohon yang sulit diubah, tingkat pendidikan dan pengetahuan yang rendah serta ketersediaan tenaga kerja untuk melaksanakan kegiatan yang berkaitan dengan penerapan teknologi yang baru.

\section{Adopsi dan Partisipasi Masyarakat dalam Penerapan Teknik Konservasi Lahan}

Dari wawancara di lapangan diketahui bahwa sebagian besar masyarakat masih mengharapkan bantuan baik itu bibit, pupuk maupun upah tenaga kerja. Ini berarti share masyarakat cukup rendah karena hanya menyediakan lahan. Kenyataan ini menunjukkan bahwa partisipasi masyarakat dalam kegiatan konservasi tanah dan air yang direncanakan masih rendah.

\section{Rekomendasi Pengelolaan Lahan}

Rekomendasi pengelolaan lahan disusun untuk mengurangi laju erosi yang terjadi, dengan mempertimbangkan faktor kemiringan lereng, penggunaan lahan yang ada saat ini (existing), arahan fungsi pemanfaatan lahan, maupun kemungkinan biaya dan tenaga yang digunakan. Pada kemiringan lereng klas II, III, dan IV dipilih menggunakan teras gulud, sedangkan untuk kemiringan lereng klas $\mathrm{V}$, menggunakan teras gunung. Dipilinya jenis teras ini dari pada teras bangku karena lebih murah dan membutuhkan tenaga sedikit.

\section{Konservasi Teknis \\ Teras Gulud}

Bagian-bagian dari teras gulud terdiri atas guludan, saluran air, dan bidang olah (Gambar 1.).

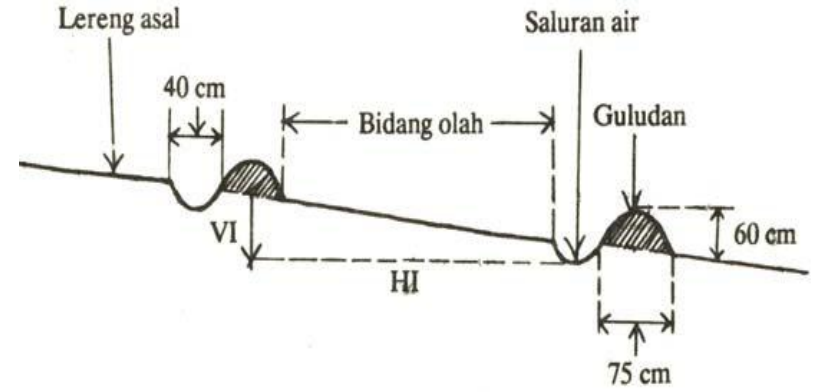

Gambar 1. Sketsa penampang samping teras gulud

Teras ini berfungsi menahan laju aliran permukaan dan meningkatkan penyerapan air ke dalam tanah. Untuk meningkatkan efektivitas teras gulud dalam menanggulangi erosi dan aliran permukaan, guludan diperkuat dengan tanaman penguat teras. Sebagai kompensasi dari kehilangan luas bidang olah, bidang teras gulud dapat ditanami dengan tanaman bernilai ekonomi misalnya tanaman katuk, cabai rawit, dll.

\section{Teras Gunung}

Teras gunung adalah jenis teras untuk tanaman tahunan, khususnya tanaman pekebunan dan buah-buahan. Teras dibuat dengan interval yang bervariasi menurut jarak tanam. Pembuatan teras bertujuan untuk : (1) meningkatkan efisiensi penerapan teknik konservasi tanah, dan (2) memfasilitasi pengelolaan lahan (land management facility), di antaranya untuk fasilitas jalan dan penghematan tenaga kerja dalam pemeliharaan tanaman.

\section{Konservasi Vegetatif}

Dalam konservasi vegetatif untuk rekomendasi penggunaan lahan, faktor yang dipertimbangkan adalah kondisi penggunaan lahan yang ada dengan arahan fungsi pemanfaatan lahan yang telah ditetapkan. Secara garis besar rekomendasi yang diajukan untuk penggunaan lahan adalah sebagai berikut:

Tabel 5. Arahan Fungsi Pemanfaatan Lahan untuk tiap jenis Penggunaan Lahan

\begin{tabular}{|c|c|c|c|c|}
\hline \multirow{2}{*}{$\begin{array}{c}\text { Penggunaan } \\
\text { Lahan } \\
\text { Saat ini } \\
\end{array}$} & \multicolumn{4}{|c|}{ Arahan Fungsi Pemanfaatan Lahan } \\
\hline & KL & KP & KBTT & KBTS \\
\hline Hutan & Hutan & Hutan & $\begin{array}{l}\text { Reboisasi } \\
\text { dengan } \\
\text { tumpangsari, } \\
\text { agroforestry }\end{array}$ & $\begin{array}{l}\text { Reboisasi } \\
\text { dengan } \\
\text { tumpangsari, } \\
\text { agroforestry }\end{array}$ \\
\hline $\begin{array}{l}\text { Kebun } \\
\text { Campur/ } \\
\text { Kebun }\end{array}$ & $\begin{array}{l}\text { Reboisasi, } \\
\text { Kebun } \\
\text { campur }\end{array}$ & $\begin{array}{l}\text { Kebun } \\
\text { campur, } \\
\text { reboisasi }\end{array}$ & $\begin{array}{l}\text { Kebun } \\
\text { campur }\end{array}$ & $\begin{array}{l}\text { Kebun } \\
\text { campur }\end{array}$ \\
\hline
\end{tabular}




\begin{tabular}{|c|c|c|c|c|}
\hline \multirow{2}{*}{$\begin{array}{c}\text { Penggunaan } \\
\text { Lahan } \\
\text { Saat ini }\end{array}$} & \multicolumn{4}{|c|}{ Arahan Fungsi Pemanfaatan Lahan } \\
\hline & KL & KP & KBTT & KBTS \\
\hline \multicolumn{5}{|l|}{ Rakyat } \\
\hline Permukiman & $\begin{array}{l}\text { Kebun } \\
\text { campuran, } \\
\text { karangkitri, } \\
\text { pagar hidup }\end{array}$ & $\begin{array}{l}\text { Kebun } \\
\text { campuran, } \\
\text { karangkitri, } \\
\text { pagar hidup }\end{array}$ & $\begin{array}{l}\text { Kebun } \\
\text { campuran, } \\
\text { karangkitri, } \\
\text { pagar hidup }\end{array}$ & $\begin{array}{l}\text { Kebun } \\
\text { campuran, } \\
\text { karangkitri, } \\
\text { pagar hidup, } \\
\text { apotik hidup. }\end{array}$ \\
\hline Sawah & Sawah & Sawah & Sawah & Sawah \\
\hline Tegalan & $\begin{array}{l}\text { Reboisasi, } \\
\text { hutan rakyat, } \\
\text { agroforestry }\end{array}$ & $\begin{array}{l}\text { Kebun } \\
\text { Campur/ } \\
\text { agroforestry, } \\
\text { reboisasi }\end{array}$ & $\begin{array}{l}\text { Kebun } \\
\text { campur, } \\
\text { tegalan }\end{array}$ & $\begin{array}{l}\text { Kebun } \\
\text { campur, } \\
\text { tegalan }\end{array}$ \\
\hline
\end{tabular}

Tabel 6. menunjukkan besarnya nilai erosi yang bisa dikurangi jika pada lahan-lahan dengan tingkat bahaya erosi tinggi (sangat berat, berat, sedang) dilakukan rekomendasi pengelolaan lahan.

Tabel 6. Besarnya pengurangan laju erosi yang terjadi jika dilakukan pengolahan lahan berdasar rekomendasi

\begin{tabular}{|c|c|c|c|}
\hline TBE & $\begin{array}{c}\text { EROSI (A) } \\
\text { saat ini } \\
\text { (ton/ha/tahun) }\end{array}$ & $\begin{array}{c}\text { Erosi sesuai } \\
\text { rekomendasi } \\
\text { (A') } \\
\text { (ton/ha/tahun) }\end{array}$ & $\begin{array}{c}\text { Pengurangan } \\
\text { erosi yang } \\
\text { terjadi } \\
\text { (ton/ha/thn) }\end{array}$ \\
\hline B & $31.083,38$ & 935,66 & $30.147,72$ \\
\hline S & $25.905,04$ & 713,98 & $25.191,06$ \\
\hline SB & $201.504,78$ & $8.836,94$ & $192.667,84$ \\
\hline Total : & $258.493,20$ & $10.486,58$ & $248.006,62$ \\
\hline
\end{tabular}

Sumber : Pengolahan dan analisis data

Apabila TBE saat ini dibandingkan dengan TBE setelah pengelolaan, nampak bahwa unitunit lahan yang semula memiliki TBE tinggi (kategori sangat berat, berat, dan sedang) dengan dilakukan rekomendasi pengelolaan lahan akan terjadi penurunan laju erosi yang signifikan. Di beberapa unit lahan masih ditemui TBE berat meski sudah dilakukan rekomendasi pengelolaan lahan. Hal ini mungkin disebabkan oleh sifat fisik lahan alami yang memang rentan erosi.

\section{KESIMPULAN DAN REKOMENDASI}

Dari hasil penelitian dan pembahasan, dapat diambil kesimpulan sebagai berikut :

1. TBE di Sub DAS Sani DAS Juwana yang memerlukan tindakan konservasi sebesar 4.425.92 Ha $(17,42 \%)$, yang terdiri dari TBE sangat berat, berat, dan sedang, tersebar di daerah yang seharusnya menjadi lahan konservasi. Erosi ini terutama disebabkan oleh konversi lahan hutan ke bukan hutan, pengelolalaan lahan pertanian kurang atau tidak memperhatikan kaidah konservasi tanah dan air, dan belum adanya kesadaran partisipasi masyarakat dalam mengelola lahannya.

2. Berdasarkan hasil rekomendasi pada unit lahan-unit lahan dengan TBE sangat berat, berat, dan sedang, laju erosi dapat dikurangi sebesar 248.006 ton/ha/tahun. Upaya pengelolaan lahan dengan teknik konservasi yang sesuai dan memadai dapat mengurangi laju erosi.

\section{Rekomendasi}

1. Untuk mengurangi laju erosi dan pengelolaan lingkungan yang berkelanjutan, maka ada beberapa hal yang bisa dilakukan : Petani dalam mengolah lahannya agar memperhatikan kaidah konservasi tanah dan air, dengan cara melaksanakan konservasi lahan secara vegetatif dan mekanik.

2. Petugas penyuluh meningkatkan kegiatan penyuluhan dan sosialisasi agar pengelolaan lahan lebih berhasil optimal.

3. Pemerintah perlu membuat demonstrasi plot teknik konservasi sehingga masyarakat dapat melihat pola tanam yang menguntungkan.

\section{DAFTAR PUSTAKA}

BP DAS Pemali Jratun, 2007, Urutan DAS Prioritas Pemali Jratun 2007, BP DAS Pemali Jratun, Semarang

Departemen Kehutanan : 2005, SK. No. 346/Menhut-V/2005 tentang Kriteria Penetapan Urutan Prioritas DAS, Departemen Kehutanan, Jakarta

Direktorat Kehutanan dan Sumberdaya Air, 2005, Kajian Model Pengelolaan Daerah Aliran Sungai (DAS) Terpadu, Departemen Kehutanan-Jakarta

Wischmeier, Smith., (1978). Predicting Rainfall Erosion Losses, United States Department of Agriculture. 